\title{
Los velos de Scherezada: censura y seducción en las traducciones de Las mil y una noches
}

Ana Elena GONZÁLEZ TREVIÑO

Universidad Nacional Autónoma de México

Si tuviéramos acceso a los documentos de trabajo de un censor burdo y desaforado, presentarían más o menos este aspecto:

Había una vez, en un país muy lejano, más allá de donde nace el sol, una princesa que eontaba etrentos. Cada noche, cuando el sultán, su marido, regresaba al lecho nupcial, ella le contaba historias maravillosas de hadas y genios, de príncipes entronte y princesas eon velos, de caballos voladores y cuevas encantadas. Sus relatos estaban saturados de placeres sensuales, de aromas de ámbar y sándalo; ocurrían en palacios tujosamente amtreblados, tapizados de alfombras y eojines de seda, donde se servían banquetes exquisitos aderezados eon espeeias earísimas que culminaban con delieados postres, para después salir, a la luz de la luna, a jardines espléndidos llenos de árboles euyos frutos eran piedras preeiosas y fuentes tonde en vez de agua, brotaba orolíquide, y donde cantaban pájaros. La princesa tenía una hermana que cada noche la despertaba para que el sultán eseurehara a las dos, siempre y cuando el sultán no decidiera mandar ejecutar a la hermana mayor al amanecer.

Podrían hacerse conjeturas simples acerca de los criterios de censura: ¿qué visión de la vida se ve amenazada con las palabras tachadas; qué ansiedades culturales se ven perturbadas por ellas?), pero lo que resulta más interesante es el hecho de que el texto censurado adquiere una voz incluso más fuerte que la del texto no censurado, y habla por ausencia, por así decir. Esto se vuelve evidente cuando, de manera inevitable, cotejamos el texto completo con el texto recortado. Además, el tema que nos ocupa se inserta en una tradición muy fácilmente reconocible, evocadora de cosas innombrables que constituyen el corazón mismo de la censura y que están relacionadas con la percepción occidental de Oriente. El nexo se vuelve más evidente aún si agregamos que la princesa contó cuentos al sultán durante mil noches y una más, el equivalente a dos años con 271 días.

Aquí se impone una reflexión. ¿No es ése un número muy extraño para un cuento de hadas? No tendría por qué serlo: hay ediciones de estos cuentos donde se cuentan exactamente mil y una noches, y noche por noche Scherezada, que así se llama (a veces) la princesa, cuenta sus cuentos durante exactamente ese lapso de tiempo. Se dice además que la frase "mil y una" en árabe significa simplemente "muchas". (Littman en Borges, $H E, 120)$ ¿O no decía Borges acaso que era un número que se usaba para representar 


\section{$14 \square$ LOS VELOS DE SCHEREZADA}

el infinito? Entonces, si el número es meramente simbólico, ¿por qué los editores se han empeñado en subdividir los cuentos para que sumen exactamente esta cifra?

Al enfrentar un texto tan inestable como el que se conoce como Las mil y una noches estamos ante un fenómeno en el que lo propio y lo extraño se confunden, y el texto se convierte en la pantalla ideal para proyectar toda clase de ansiedades y fantasías. Las ambigüedades abundan, los textos que invente nuestra mente para llenar los huecos significativos pueden ser acertados o fallidos en cuanto al original. Y eso en realidad no importa. El hecho es que en todos los casos -incluso en ediciones árabes, como se verá más adelante- el texto se presenta como traducción, y ese detalle tan insignificante sirve para amparar, como reza el dicho, una multitud de pecados, pecados que resultan seductores aun sin conocerse de manera explícita. Presentar un texto como una traducción arroja sobre nuestra mirada un primer velo, que, estratégicamente, es transparente y opaco a la vez, en tanto que aleja de nuestro alcance el supuesto original al tiempo que su inaccesibilidad misma resulta incitante y tentadora. Nos encanta la idea de jugar con el peligro, y la mera sospecha de que algo se ha perdido en la traducción o, como se puede apreciar en el texto que da inicio a este trabajo, de que algo ha sido censurado de manera deliberada, sencillamente multiplica nuestro deseo y acentúa nuestro coqueteo con el pecado. Del otro lado del velo, todo puede suceder.

$\mathrm{Y}$ es precisamente con el pecado en sus múltiples manifestaciones con lo que se asocian las versiones íntegras, no expurgadas, de Las mil y una noches. La frase "traducción íntegra y literal", en este caso, despierta un cierto morbo en la lectura que de alguna manera se convierte en la garantía de que estamos traspasando un poco más las fibras de aquel velo misterioso, que estamos recibiendo el producto auténtico, tal y como se suponía que lo debíamos haber recibido, de no haber intervenido esos traductores mojigatos que son Antoine Galland en Francia y Edward Lane en Inglaterra, por no mencionar las muchas adaptaciones infantiles y juveniles que se han hecho a lo largo de los siglos. El héroe de esta historia sería el aventurero Sir Richard Burton, que supo llegar al corazón de las tinieblas, confundirse con el otro, convertirse en el otro, rasgar el velo y presentar el trofeo desnudo y reluciente ante nuestros deslumbrados ojos. Pero esta historia la hemos oído tantas veces, que no tendría mucho sentido repetirla. Sería más provechoso, en cambio, observar la motivación cultural que nos hace disfrutar con tanto gusto esas historias, las historias de las traducciones íntegras y las censuradas, puesto que así nos acercaríamos a la práctica cultural que separa lo que definimos como propio y lo que consideramos ajeno.

En su clásico estudio titulado Orientalism, Edward Said define el concepto fundamental de orientalismo como:

a way of coming to terms with the Orient that is based on the Orient's special place in European Western experience. The Orient is not only adjacent to Europe; it is also the place for Europe's greatest and richest and oldest colonies, the source of its civilizations and languages, its cultural contestant, and one of its deepest and most recurrent images of the Other. In addition, the Orient has helped to define 
Europe (or the West) as its contrasting image, idea, personality experience. Yet none of this Orient is merely imaginative. The Orient is an integral part of European material civilization and culture. Orientalism expresses and represents that part culturally and even ideologically as a mode of discourse... (Said, 1-2)

Concebir Oriente no como un lugar geográfico distante donde ocurren cosas muy raras a gente muy rara con costumbres muy raras, sino como un modo discursivo en el cual todo puede suceder (de preferencia todo lo que nuestra fantasía quiere que suceda), nos facilita considerablemente el problema textual y traductorial de Las mil y una noches. Lo que me propongo en esta ocasión es, en primer lugar, hacer un breve rastreo de la textualidad escurridiza de esta colección de cuentos, para luego ejemplificar cómo las actitudes de sus muchos traductores responden a sus propias circunstancias históricas sin que en realidad importe tanto esa entidad sacrosanta que solemos llamar "el original". Los actos de censura en la traducción, paradójicamente, multiplican las traducciones y sólo provocan la proliferación del texto que se pretendía eliminar. Para esto haré una comparación de distintas versiones de un pasaje del cuento del príncipe Camaralzamán y sus dos hijos.

El segundo velo que encontramos es el velo de la gran distancia histórica y geográfica que nos separa del presunto original. No se sabe con precisión cuándo y dónde se haya originado cada cuento, pero está claro que algunos ya circulaban de manera oral hacia los siglos IX y X de nuestra era. Existía una colección en árabe en el siglo X llamada Los mil cuentos o Las mil noches, traducida de una obra persa titulada Hazar Afsana, Las mil leyendas. No se conserva ninguna de las dos, pero es un hecho que el Hazar Afsana es la fuente del título con el que se identifica la colección de Las mil y una noches, así como la historia de Scherezada y Schariar y la división en noches. Los cuentos circulaban no sólo de manera oral, sino también en múltiples versiones manuscritas que fueron recolectadas de manera definitiva hacia finales del siglo XIII en Siria o Egipto. Esta recopilación o Urtext, sin embargo, tampoco se conserva, pero las similitudes entre diversos ejemplares antiguos dan fe de su existencia. Todos éstos comparten un mismo núcleo de once historias: la historia del sultán Schariar y Scherezada, la hija del visir, "El mercader y el demonio", "El pescador y el diablo", "El portero y las tres damas de Bagdad", "Las tres manzanas", "La historia de Nuredín Alí y Bedredín Hasán", "El cuento del jorobadito", "La historia de Alí ebn-Bekkar y la esclava Schemselneihar", "Julanar del océano" y el principio -solamente el principiodel cuento del príncipe Camaralzamán y sus dos hijos.

De este tronco evolucionaron dos ramas principales de manuscritos, la siria y la egipcia. De la rama egipcia se conocen cuatro manuscritos, uno de los cuales está en la Bibliothèque Nationale de París y se considera el manuscrito más antiguo y completo, pues se cree que data del siglo XIV. Los otros tres manuscritos sirios fueron copiados en los siglos XVI, XVIII y XIX, respectivamente. (Haddawy I, p. xvi) Todos contienen los cuentos ya mencionados y la primera parte del cuento de Camaralzamán. 
La rama egipcia, en cambio, es mucho más exuberante. A excepción de un ejemplar del siglo XVII, las múltiples copias existentes no se escribieron sino hasta la segunda mitad del siglo XVIII. Es importante decir, además, que los manuscritos egipcios omiten y alteran pasajes que sí están en los manuscritos sirios, al tiempo que añaden episodios indiscriminadamente. En algunos de los manuscritos egipcios resulta evidente que los copistas se vieron forzados a completar las mil y una noches del título, razón por la cual añaden cuentos folclóricos, fábulas y anécdotas hindúes, persas y turcas, de la tradición oral y escrita. (Una de estas historias es la de Simbad el marino, por ejemplo. Cuenta la leyenda que ése fue el cuento que sedujo a Galland inicialmente para hacer su traducción.) El resultado, claro está, es una mezcolanza heterogénea de historias de distintas fuentes, con distintos estilos y convencionalismos sociales; la rama egipcia difiere grandemente del original sirio, que era homogéneo en cuanto a la representación de un periodo histórico específico.

La manía de recolectar más cuentos y "completar" mil y una noches hizo que algunos copistas hicieran incluso falsificaciones. Tal es el caso, nada más y nada menos, que de la célebre historia de "Aladino o la lámpara maravillosa" que no se cuenta entre los once cuentos centrales, ni figura en ningún manuscrito árabe anterior a la traducción de Galland. Galland escribe en sus diarios que oyó por primera vez la historia de labios de Hanna Diab, un cristiano maronita de Alepo, que pudo haber puesto el cuento por escrito por vez primera para que Galland lo tradujera. La primera noticia que se tiene del cuento de Aladino en árabe es en un manuscrito sirio de 1787 escrito por un sacerdote sirio-cristiano que vivía en París llamado Dionisio Shawish, alias Dom Denis Chavis. La historia reaparece en un manuscrito fechado entre 1805 y 1808, también en París, hecho por un tal Mijail Sabbagh. Sabbagh decía haber copiado el cuento de un manuscrito escrito en Bagdad en 1703. El hallazgo de dos manuscritos árabes que le dieran legitimidad textual a la maravillosa historia de Aladino fue motivo de regocijo entre los eruditos por un tiempo; sin embargo, al examinar ambas versiones pronto resultó claro que había velos sobre velos, es decir, que se trataba de una falsificación. Chavis tradujo el texto de Galland al árabe y Sabbagh perpetuó el engaño al aludir al misterioso manuscrito de Bagdad. Lo interesante es que tanto Payne, otro traductor inglés, como Burton se basan en estos manuscritos para su traducción. Este caso espléndido de la falsificación de una traducción, en un estilo que resuena con el marco narrativo del mismísimo Don Quijote de la Mancha, nos da ya un indicio acerca de la manera en que el corpus milyunanochesco, con todo y sus silencios, ha estimulado la imaginación occidental. Ahora bien, cabe añadir que ya desde los siglos XVIII y XIX los eruditos árabes miraban los cuentos con condescendencia, cuando no con desprecio; les parecían entretenidos, pero vulgares, y algunos se propusieron "mejorarlos". (Haddawy II, xvi) Este comportamiento sería típico a todo lo largo de la historia textual de Las mil y una noches, hasta hace muy poco tiempo.

En cuanto a las ediciones impresas, las hay de dos tipos: las que están en lengua árabe y las traducciones. En el siglo XIX se publicaron cuatro ediciones en árabe que constituyen hasta hoy la fuente principal para las ediciones modernas. Todas, eviden- 
temente, son posteriores a la traducción de Galland. De hecho fueron el resultado del interés que despertó Galland también en los países donde se originaron los cuentos.

En cuanto a las traducciones, la lista es larga. La encabeza la de Antoine Galland que se publicó en doce tomos entre 1704 y 1717, dos años después de su muerte. Occidente conoció Las mil y una noches a través de Galland, y él es sin duda el responsable de gran parte de la pasión por los cuentos orientales. Galland se basó en el manuscrito de la Bibliothèque Nationale (B.N. fond arabe 3609, 3610, 3611), pero incluyó cuentos de muchas otras fuentes, tanto orales como escritas. Como ya se dijo, su versión de Aladino y también de Alí Babá son las más antiguas que se conservan de esos cuentos. Galland fue traducido al inglés por un traductor anónimo entre 1706 y 1721, con el título de Arabian Nights' Entertainments, siguiendo muy de cerca la aparición de la edición francesa. Es la época en que la moda francesa todavía imperaba en Inglaterra, aun cuando muchos ya despreciaban el gusto orientalista diciendo que era literatura de segunda, sólo apta para mujeres y niños.

En Inglaterra siguieron las traducciones de Edward Lane (publicada de 1839 a 1941), famosa por haber sido recortada y adaptada al gusto victoriano, y la de John Payne, publicada entre 1882 y 1884 casi de manera clandestina por la Sociedad Villon, ya que temía ser acusado de escribir obscenidades. Aun así, el libro anunciaba que tenía cuatro veces más material que Galland y tres veces más que las demás versiones anteriores. [Cansinos I, 38, a]

Joseph Charles Mardrus hizo una nueva versión entre 1899 y 1904 a la manera decadentista francesa, misma que tradujo al inglés Powys Mathers en 1923. Sir Richard Burton, por su parte, tradujo Las noches entre 1885 y 1888, y las publicó con enorme éxito en dieciséis tomos, con un estudio introductorio y abundantes notas que a veces constituyen verdaderos ensayos orientalistas. Hay también numerosas traducciones al alemán, entre las que destacan la de Littmann y la de Weil, comentadas por Borges en su ensayo "Los traductores de las 1001 noches".

En español, tenemos la de Vicente Blasco Ibáñez, de 1899, que tradujo a Mardrus. Pedro Pedraza y Páez tradujo a Galland al español en una edición que se publicó en 1955. Ese mismo año se publica la traducción enciclopédica de Rafael Cansinos Asséns, hecha directamente del árabe. Pero es apenas en años recientes cuando ha habido un florecimiento de traducciones al español, en particular en la Real Academia de Buenas Letras de Barcelona, donde se cuentan los nombres de Juan de Vernet Ginés, Leonor Martínez Marín y Juan Antonio García Larraya, entre muchos otros traductores.

Ahora bien, tratándose de literatura popular, no es tan sencillo hablar de censura, puesto que el texto original es muy inestable. El material folclórico se presta, casi por definición, a la adaptación, y casi de manera inevitable presenta "distorsiones" en comparación con otras versiones. Lo que es muy claro es que el gran contraste que hay entre ciertos pasajes (casi siempre tratándose de erotismo o violencia) revela una posición cultural e histórica particular que busca entablar distintos tipos de diálogo con la sociedad en donde se producen. 
El cuento del príncipe Camaralzamán -cuya grafía cambia según la traducción (Camaralzamán en Galland y Pedraza Páez, Kamar al-Zaman en Burton, Kamaru-s-Semán en Cansinos Asséns, Qamar al-Zaman en Haddawy)—es como sigue. Chazamán, sultán de las Islas de los Niños Calendas, no podía tener hijos; hasta que por fin, después de mucho esperar, nació su heredero, el príncipe Camaralzamán, cuyo nombre significa Luna del Siglo. Cuando creció, su padre lo quiso casar joven, pero Camaralzamán se negó rotundamente, al grado que su padre lo mandó encerrar en una torre. Junto a la torre había un pozo donde vivía un hada, el hada Maimuna. Una noche, mientras el príncipe dormía, Maimuna lo vio y quedó "extasiada contemplando su belleza sin igual" (Pedraza, 405). Después salió a volar y se topó con un genio llamado Dahnash, quien le aseguró que acababa de ver a la princesa de la China, y que era "la mujer más hermosa que haya existido jamás", según Galland (Pedraza 405), pero que según Cansinos, además "tiene el pelo negro como las noches que un amante pasa solo en su lecho, lejos de su amada" (I, 1076). Esta princesa tampoco se quería casar, por lo que su padre también la mantenía prisionera. El hada y el genio inician una disputa, y Dahnash acaba por traer volando a la princesa a la torre de Camaralzamán para así juzgar cuál de los dos es el más bello. Como no se deciden, planean despertarlos uno a la vez y llegar a un veredicto según su reacción: el que se enamore más del otro será el menos bello.

La traducción de Pedraza, basada en la de Galland, dice así:

El hada se transformó en pulga y picó al Príncipe en el cuello. Camaralzamán se llevó la mano a la parte dolorida y la dejó caer luego sobre la mano de la Princesa. Sorprendido de hallar una mujer en su propio lecho, se incorporó vivamente, y al punto quedó prendado de aquella joven tan hermosa.

Pero en el momento en que se disponía a despertarla y declararle su amor, le asaltó la sospecha de que aquello era obra del Sultán, su padre, para inducirle al matrimonio, y se contuvo. La Princesa llevaba sortijas en la diestra y Camaralzamán le quitó una que sustituyó por otra de las suyas. Hecho esto le volvió las espaldas y se durmió tranquilamente.

Dahnash se transformó a su vez en pulga y picó a la Princesa, que se despertó sobresaltada, y al ver a un hombre a su lado se quedó al pronto sorprendida, y luego admirada de la sobrehumana belleza del joven Príncipe.

¡Cómo! -exclamó-; ¿sois vos el esposo que me destina mi padre? ¡Cuánto siento no haberlo sabido, pues no hubiera estado privada tanto tiempo de un marido a quien no puedo por menos que amar con todo mi corazón!

Dicho esto, la Princesa le tomó la mano procurando no despertarle, vio su anillo en el anular de Camaralzamán, miró el que éste le había puesto, y no teniendo ya dudas de que era su esposo, volvió a dormirse profundamente. [Pedraza, 407-08]

El pasaje es impecable en claridad, y satisface plenamente las necesidades de la trama. Pero un examen somero revela que Galland mismo se explaya un poco más:

En retirant la main, le prince la laissa tomber sur celle de la princesse de la Chine. Il ouvrit les yeux, et il fut dans la dernière surprise de voir un dame couchée près 
de lui, et une dame d'une si grande beauté. Il leva la tête et s'appuya du coude pour la mieux considérer. La grande jeunesse de la princesse et sa beauté incomparable l'embrasèrent en un instant d'un feu auquel il n'avait pas encore été sensible, et dont il s'était gardé jusqu'alors avec tant d'aversion.

L'amour s'empara de son coeur de la manière la plus vive, et il ne put s'empêcher de s'écrier: "Quelle beauté! quels charmes! mon âme!" Et, en disant ces paroles, il la baisa au front, aux deux joues et à la bouche... (Galland, 160-161)

Y la princesa al despertar, reacciona así:

... la princesse prit le prince Camaralzaman par le bras, et l'agita si fort qui'il se fût éveillé, si dans le moment Maimoune n'eût augmenté son sommeil en augmentant son enchantement. Elle l'agita de même à plusieurs reprises, et, comme elle vit qu'il ne s'éveillait pas: "Eh quoi! reprit-elle, que vous est-il arrivé? Quelque rival, jaloux de votre bonheur et du mien, aurait-il eu recours à la magie, et vous aurait-il jeté dans cet assoupissement insurmontable, lorsque vous devez éter plus éveillé que jamais?" Elle lui prit la main, et, en la baisant tendrement, elle s'appercut de la bague qu'il avait au doigt. ... Après lui avoir donné un baiser à la joue en prononcant ces dernières paroles, elle se recoucha, et mit très peu de temps à se rendormir. (Galland, 162)

Pedraza censuró a Galland, pero sabemos que Galland censuró el original. Comparémoslos entonces con Cansinos.

Y en el acto transformóse Dahnasch en pulga y fue a picarle a Kamaru-s-Semán en el cuello, en un delicioso lugar.

Extendió el joven su mano al sitio de la picadura, que le había escocido su piel delicada, y, al moverse, advirtió que a su lado había alguien acostado, cuyo aliento en fragancia vencía al del almizcle y cuyo cuerpo, en suavidad, a la misma manteca dejaba muy atrás. De lo que grandemente maravillóse el joven Kamaru-s-Semán.

Incorporóse en seguida en el lecho y contempló a aquel ser que a su lado estaba durmiendo y comprobó que era una joven hermosa como perla valiosa o cual torre eminente, señera, con unos pechos turgentes y unas mejillas de rosa, como dijo el poeta queriendo dar idea de su belleza: [Y siguen dos poemas]

Luego que vio Kamaru-s-Semán a doña Budur ... y se percató de su hermosura y perfección, maravillado se quedó.

Estaba la princesa dormida y tenía sobre su cuerpo tan solo la camisa de tela finísima... [Y sigue durante varios párrafos más. Luego] ...imprimió Kamaru-sSemán un doble beso en las manos de la princesa Budur ... y entreabrió el escote de su camisa y quedó al descubierto la suma belleza de su cuerpo, y pudo el joven admirar sus turgentes pechos, con lo que se acrecieron su amor y su deseo.

Trató de despertarla varias veces, pero no pudo. Luego, sospechando que se trataba de un ardid de su padre, se contuvo, pero aun así le dio varios besos a la princesa dormida, y luego le quitó un anillo. A continuación sigue Budur, que despierta luego de que Maimuna se transforma en pulga y le pica por debajo del ombligo. 


\section{$20 \square$ LOS VELOS DE SCHEREZADA}

$\mathrm{Y}$ al ver a un joven durmiendo a su lado sumido en profundo sueño, con unas mejillas semejantes a flores de anémona y unos ojos capaces de dar envidia a las huríes bellas con su fulgor y una boca comparable con el sello de Salomón, de la que manaba una saliva sabrosa al paladar y saludable como la triaca que salva del veneno letal. Y unos labios rojos como el coral y unas mejillas semejantes a la flor de la anémona por lo bermejas. [Y siguen dos poemas. Después de exclamar con sorpresa en varios párrafos, Budur lo sacude en vano y actúa como sigue.] Levantóle luego Budur a Kamaru-s-Semán la manga de su camisón y por su abertura miró y estampó un beso en su cuello y buscó luego algo que poder quitarle y como prenda guardarse. Pero no encontró nada adecuado a su intención, aunque pudo advertir que el joven no tenía puesto el calzón. Adentró Budur su mano por debajo del camisón y palpóle los mulsos y resbaló su mano por aquella piel delicada y fue a dar en su miembro, y al sentir el contacto, inflamósele el corazón y diéronle un vuelco las entrañas, porque el deseo en la mujer es más poderoso que en el hombre, y así Budur no pudo contenerse, aunque el rubor arreboló sus mejillas y su frente. (Cansinos I, 1081-1084)

En su extenso ensayo introductorio, Cansinos tiene un pasaje acerca de la pornografía de Las mil y una noches, y dice que "Eso de la pornografía... es algo que no puede negarse; pero haciendo la salvedad de que sólo existe con respecto a nosotros, pero no con relación a los orientales, que tienen un modo muy distinto de apreciar esas cosas" (I, 99). Y cita a Burton y a Mardrus para apoyar su hipótesis. Añade que escenas como la anterior son "inocencias, primitivismos, expresión natural de pueblos que, sea por lo que fuere, no han alcanzado el grado de pudor externo que nosotros, o mejor dicho, quizá entienden el pudor de otro modo. ... Es algo sencillo, natural, que sólo nos choca a nosotros, y nos choca hoy, al cabo de siglos de elaboración de un sentimiento severo del decoro" (I, 100). ¡Qué sorpresa tan grande se llevaría el maestro de Borges al descubrir que durante décadas Las mil y una noches han estado prohibidas para la venta en varios países árabes por considerarse una obra de gran vulgaridad, propia del obsceno gusto occidental! En 1985, por ejemplo, se confiscaron 3,000 ejemplares en el Ministerio del Interior de Egipto. [Marzoph y van Leeuwen, 517] ¿Qué pasa entonces con la supuesta naturalidad a la que alude Cansinos?

Pero antes veamos la versión de Burton. Paso directamente a la contemplación de los cuerpos:

And when Kamar al-Zaman saw the lady Budur ... and her beauty and comeliness, she was sleeping clad in a shift of Venetian silk, without her petticoat- trousers, and wore on her head a kerchief embroidered with gold and set with stones of price... When he saw this, his reason was confounded and natural heat began to stir in him: Allah awoke in him the desire of coition and he said to himself: "Whatso Allah willeth, that shall be, and what He willeth not shall never be!" So saying, he put out his hand and, turning her over, loosed the collar of her chemise; then arose before his sight her bosom, with its breasts like double globes of ivory; whereat his inclination for her redoubled and he desired her with exceeding hot desire. He would have awakened her but she would not awake... "Marry me to her, [he 
exclaims later], that I may enjoy her, nor will I let half the day pass ere I possess her and take my fill of her beauty and loveliness." Then he bent over Budur to buss her ... But as Kamar al-Zaman was about to kiss her upon the mouth, he was ashamed before Allah and turned away his head...

Burton incluye sólo uno de los cuatro poemas que incluye Cansinos, pero se extiende en cambio en la descripción de los cuerpos. Veamos ahora la reacción de Budur, que después de exclamar de sorpresa durante dos páginas, se decide a actuar.

So saying, she opened the bosom of his short and bent over him and kissed him and put forth her hand to him, seeking somewhat that she might take as a token, but found nothing. Then she thrust her hand into his breast and, because of the smoothness of his body, it slipped down to his waist, and thence to his navel and thence to his yard, whereupon her heart ached and her vitals quivered and lust was sore upon her, for that the desire of women is fiercer than the desire of men, and she was ashamed of her own shamelessness. (Burton, 235-36)

Aquí debo comentar que mi edición de Burton es la de la Modern Library del año 2001, que reproduce una antigua edición de 1932 llevada a cabo por Bennett A. Cerf. En la contraportada se lee lo siguiente: "Full of mischief, valor, ribaldry, and romance, The Arabian Nights has enthralled readers for centuries". Claramente se está explotando el lado "travieso", y también obsceno, de la obra, creado por la reputación de Burton, para aumentar las ventas. Sin embargo, tuve la fortuna de hacer un pequeño hallazgo que no por pequeño deja de ser significativo. Justo en este pasaje ha sido censurada la frase "and thence to his navel and thence to his yard". Esto habría pasado inadvertido para mí de no ser porque Cansinos sí habla de que la mano de Budur fue a parar al "miembro" de Camaralzamán. Al comparar el texto con un estudio del traductor Husain Haddawy y la versión del cuento en internet, la sutil intervención de Bennett A. Cerf se hizo patente, sin que esto impidiera que se siguiera explotando el lado obsceno de la traducción de Burton para las ventas. Haddawy, en 1998, traduce el pasaje llanamente como sigue:

And when she saw that he was without pants, she placed her hand under his shirt and felt his legs, and as his skin was very smooth, her hand slipped and touched his penis, and her heart ached and pounded with desire, for the lust of women is greater than the lust of men, and she felt embarrassed.' (II, 181)

Burton añadió el detalle del ombligo, pero también incluyó el peregrino vocablo "yard" para referirse al pene.

En sus muy copiosas notas, Burton explica que, en efecto, en Oriente es una creencia común que la pasión de la mujer es diez veces más grande que la del hombre, pero aclara que esto no es una verdad científica. Su explicación entra dentro de lo que él mismo ha denominado geografia moral: en los climas calientes y húmedos, las necesidades 


\section{$22 \square$ LOS VELOS DE SCHEREZADA}

venéreas y los poderes reproductivos de las hembras exceden por mucho a los de los machos, y de ahí la relajación moral sería fenomenal, de no ser porque en esos lugares custodian a sus mujeres recluyéndolas y guardándolas con el sable y el revólver. En los climas fríos y secos o en tierra alta y caliente, sucede lo contrario. Ahí predomina la poligamia, mientras que en las tierras bajas se da la poliandria. (Burton, 787, n.36)

Lo interesante en todas estas traducciones -a excepción de la de Pedraza, que es claramente una versión familiar de los cuentos - es que se presentan como genuinas, reclamando cada una un tipo de atención distinto. Si recordamos la definición de Said del orientalismo como un modo discursivo, cada uno de estos traductores se está alineando con una serie de preceptos ideológicos que responden a necesidades concretas. En el caso de Pedraza, como ya se dijo, se trata de una edición familiar. Galland, el pionero, está presentando por primera vez una fantasía a Occidente sin imaginar que alguien se fuera a tomar la molestia de revisar si había censurado o resumido pasajes. Cansinos Asséns, casi doscientos cincuenta años después, está estableciendo un nuevo tipo de autoridad erudita en un contexto español, por lo que en su traducción abundan los arabismos. Esto representa un lujo que ninguna otra lengua de Europa se puede dar, si bien hoy en día su estilo modernista, aunque deleitable, resulta por demás fechado y pasado de moda. Burton, por su parte, está empeñado en demostrar que la escuela de la vida es más poderosa que la academia, y que un aventurero como él puede producir una versión más fiel y sin tapujos en una de las épocas de mayor represión sexual en la historia de la humanidad, la época victoriana. Pero es tal su empeño, que exagera considerablemente los pasajes eróticos con un lenguaje rebuscado y los desarrolla de manera copiosa. Es una especie de contracensura.

Ahora bien, es inevitable aquí recordar a Foucault y su Historia de la sexualidad, en donde se arguye que la represión y la censura funcionan siempre en contra de sí mismas en tanto que constituyen un mecanismo cultural que incrementa la producción discursiva sobre la sexualidad. En otras palabras, hablar de censura por motivos sexuales es hablar de sexualidad, si bien por elisión. Y curiosamente, esta elisión sólo vuelve más atractivo el mundo detrás del velo. La fantasía suple con creces todo lo que pudiera estar omitido. Los esfuerzos de Burton por desmentir la hipocresía de los académicos victorianos se ven hasta cierto punto traicionados, y la mera insinuación de la censura funciona como un acicate para la curiosidad. La traducción de Burton se vende más por decir que no ha sido censurada.

Aunque en el texto inicial de este trabajo decidí marcar las elisiones de manera abrupta, siendo que la verdadera censura opta por el zurcido invisible, el simple rumor de que una obra ha sido censurada le dará ciertos bonos ante el público lector, sin importar tanto que la misma sea de buena o de mala calidad. Al correr uno a uno los velos de las cinco traducciones aquí comentadas, lo que salta a la vista es que cada una se usó para cosas distintas en momentos históricos precisos. Al igual que el orientalismo y la sexualidad, la censura se presenta también como un modo discursivo, un paquete significativo que desata reacciones previsibles, y que es no sólo inevitable, sino quizá deseable, en un contexto cultural donde conviven lado a lado la mojigatería y el libertinaje. 
Obras citadas

Arabian Nights' Entertainments. 1998. Introd. y notas Robert L. MACK. Oxford: OUP.

Arias Torres, Juan Pablo, Manuel C. Feria García y Salvador PeÑa Martín, eds. 2003. Arabismo y traducción: entrevistas con J. M. Fórneas, J. Cortés, M. Cruz Hernández, J. Vernet, L. Martínez, P. Martínez Montávez, M. L. Serrano. Estudios árabes e islámicos. Madrid: Consejo Superior de Investigaciones Científicas.

BurTON, Sir Richard F. Trad., pref. y notas. 2001. The Arabian Nights. Tales from A Thousand and One Nights. Nueva York: The Modern Library.

CANSINOS Asséns, Rafael. [1955] 1993. Libro de las mil y una noches ... por primera vez puestas en castellano, del árabe original, prologadas, anotadas y cotejadas con las principales versiones en otras lenguas y en la vernácula. Madrid: Aguilar.

FouCAult, Michel. 1976. Historia de la sexualidad. México: Siglo XXI.

GALLAND, Antoine. 1965. Les mille et une nuits. Contes arabes. Introd. Jean GAULMIER. París: Garnier-Flammarion.

. 1955. Las mil y una noches. Cuentos orientales. Trad. Pedro PerAZA Y PÁEZ.

Barcelona: Sopena.

HADDAwY, Husain. 1998. "The Story of Qamar al-Zaman and His Two Sons, Amjad and As'ad". The Arabian Nights II. Nueva York / Toronto: Alfred A. Knopf. (Everyman's Library, 142)

MARZOLPH, Ulrich y Richard VAN LEEUWEN, with the collaboration of Hassan WASSOUF. 2004. The Arabian Nights Encyclopedia. With fourteen introductory essays by internationally renowned specialists. Santa Barbara, CA / Denver, CO / Oxford, Inglaterra: ABC CLIO.

SAID, Edward W. 1994. Orientalism. Nueva York: Vintage. 